\title{
Güneydoğu Anadolu Bölgesi’nde Aktarlarda Satılan Papatya Türlerinin Tespitine Yönelik Bir Araștırma
}

\author{
Doğan ARSLAN( \\ Siirt Ü. Ziraat Fakültesi Tarla Bitkileri Bölümü, Kezer Yerleșkesi Siirt \\ Sorumlu yazar e-posta (Corresponding author e-mail): doganarslan@siirt.edu.tr \\ Geliș Tarihi (Received): 04.09.2019 Kabul Tarihi (Accepted): 03.12.2019
}

\section{Öz}

Bu çalıșma, Güneydoğu Anadolu Bölgesi'nde bulunan aktarlarda mayıs papatyası olarak satışı yapılan ürünlerin ismine doğru olup olmadığını belirlemek amacıyla gayeli örnekleme yöntemi kullanılarak 2018 yılında yürütülmüștür. Dünyada, Anthemis nobilis (Romen papatyası), Matricaria recutita (Mayıs papatyası) ve Ormenis multicaulis (Fas papatyası) türleri yaygın bir șekilde tıbbi amaçlı olarak kullanılmaktadır. Ancak mayıs papatyası öncelikle șifa bulmak isteyen alıcıların ülkemizde ve dünyada tercih ettiği ilk bitki olmasına rağmen, pazarda onun yerine çoğu zaman Köpek papatyasının (Cota altissima J. Gay) satılmasından dolayı tedarikçiler, perakendeciler ve özellikle tüketicilerde bilinç ve kamuoyu olușturulması amacıyla bu çalıșma yapılmıștır. Çalıșma materyali olan mayıs papatyası, genellikle soğuk algınlıklarında, öksürüklerde, midevi ve karminatif kullanım gibi amaçlarla alınıp satılmaktadır. Bu çalıșma 6 ilde (Siirt, Batman, Mardin, Diyarbakır, Gaziantep ve Șanlıurfa) faaliyet gösteren merkezi konumda, aktarlar çarșısının bulunduğu illerde aktarlar çarșısında ve müșteri yoğunluğunun fazla olduğu aktarlar gayeli örnekleme yöntemi uygulanarak seçilmiș ve toplam 60 ișyerinden örnekler alınmıștır. 60 adet aktardan satın alınan örneklerde yapılan tür teșhisi neticesinde örneklerin \%95,7'sinin köpek papatyası (Cota altissima J. Gay), sadece \%4,3'nün mayıs papatyası (Matricaria recutita) olduğu tespit edilmiștir. Çalıșma sonucunda insan sağlığı için önemli olan tıbbi ve aromatik bitkilerin tedarikçi ve perakendecilerinin hem bu konuda eğitimli olması hem de alanında yetkili uzmanlarca düzenli olarak denetime tabi tutulmaları gerektiği ortaya çıkmaktadır.

Anahtar Kelimeler: Tıbbi ve aromatik bitkiler, Mayıs papatyası (Matricaria recutita), Köpek papatyası Cota altissima (L.) J. Gay, Sağlık.

\section{A Research on Taxonomic Identification of Chamomile Species Sold in Acthars in the Southeastern Anatolian Region of Turkey}

\begin{abstract}
This study was carried out in 2018 using purposive sampling method, in order to identificate the chamomile species sold in the acthars in Southeastern Anatolian Region. Anthemis nobilis, Matricaria recutita and Ormenis multicaulis species are widely used in the world for medicinal purposes. This study was conducted to raise the public awareness among suppliers, retailers and especially consumers, due to the sale of Cota altissima as chamomile, although chamomile is the first plant preferred by consumers who wants to consume it as medicinal purposes. Chamomile species are commonly used against to cold, cough, gastric and carminative uses. Samples collected from 60 acthars were evaluated with purposeful sampling method from Siirt, Batman, Mardin, Diyarbakır, Gaziantep, and Şanlıurfa provinces. According to the results $95.7 \%$ of the samples were determined as dog chamomile (Cota altissima) and only $4.3 \%$ of them were chamomile (Matricaria recutita). In this study, it is revealed that suppliers and retailers of medicinal and aromatic plants should be informed and they should be controlled regularly by governmental specialists.
\end{abstract}

Keywords: Medicinal and aromatic plants, Matricaria recutita, Cota altissima (L.) J. Gay, Health 


\section{Giriș}

Türkiye'de Asteraceae familyasına dahil olan, sarıçiçek düğmesine ve beyaz dil çiçeklerine sahip, halk arasında kendisi ile "seviyor-sevmiyor" falı bakmak için kullanılan bütün bitkilere papatya denilmekte ve bu bitkilerden tıbbi olarak da yararlanılmaktadır. Fakat bu bitkilerden sadece Anthemis nobilis (Romen papatyası), Matricaria recutita (mayıs papatyası) ve Ormenis multicaulis (Fas papatyası) türleri yaygın bir șekilde tıbbi amaçlı olarak kullanılmaktadır (Arslan ve ark. 2015; Baydar 2013; Baytop 1999; Ceylan 1996; Hergenç 2015; Zeybek ve Haksel 2011). Bunlardan en yaygın bir șekilde yararlanılan mayıs papatyası türü binlerce yıldır Dünya'da geleneksel tıpta kullanılan bir bitkidir. Antik Mısırlılar seyahatlerinde yanlarında mutlaka mayıs papatyasından hazırlanmıș tabletler tașırlardı. Mayıs papatyasının sağlık alanında kullanımı ile ilgili bilgiler Hippocrates, Plinius, Dioscorides ve Galen'den gelmektedir. Plinius, Dioscorides ile Arap hekimleri mayıs papatyasının adınının "Chamaemelon" olduğunu bildirmektedirler (Ceylan, 1996; Gül, 1995; Salamon, 2004).

Mayıs papatyası bugün, ABD, Almanya, Avusturya, Brezilya, Slovakya, Fransa, Hollanda, İngiltere, İtalya, İsveç, İsviçre, Macaristan, Mısır, Romanya, Rus, Türk, Eski Yugoslavya ve Yunan farmakopesine kayıtlıdır. Fitoterapide kullanımı ile ilgili olarak (Chamomillae flos) 26 ülkenin farmakopesine kayıtlı olduğu bilinmektedir (Baghalian ve ark., 2008; Gül, 1995; İşman, 2009; Salamon, 2004; Pirzad ve ark., 2006).

Mayıs papatyası Asteraceae (Compositae) familyasına dahildirve bu familyadaki bitkilerinin çoğu otsu yapıda olup, az bir kısmı ağaç veya çalı formundadır (Baytop, 1996). Güner 2013'e göre, Asteraceae familyası Türkiye'de 136 cins ve 1345 tür ile temsil edilmekte olup, hem tür hem de cins bakımından floramızın en zengin familyasıdır (Abak ve Akan, 2014).

Alman papatyası olarak da bilinen bu bitki; pürüzsüz, dallı, mis gibi kokuya sahip, geniș bir ekolojiye yayılmıștır. Bir uzun gün bitkisi olan mayıs papatyasında kapitulumdaki çiçekler tüp şeklindede olup çoğunlukla süt borusu tașımamaktadır. Mayıs papatyası, Türkiye'de mayıs ayında çiçek açan, yaprakları ince parçalı tek yıllık bir bitkidir. Dilsi çiçekler beyaz, tüpsü olanlar sarı, reseptakulum koni șeklinde ve içi boștur. Kapitulumlar uçucu yağ taşımaktadır (Baytop, 1996, Rafieiolhossaini ve ark., 2010).

Çiçek tabanı genç devrede hafif daha sonra kuvvetli kubbemsi olup iç kısmı boștur ve bu özellik mayıs papatyasına benzeyen diğer Asteraceae familyası bitkilerinden önemli bir ayırt edici özelliktir (Ceylan, 1996).

Adi papatya, Ak baba, Ak babacca, Ak babaç, Ak bubaç, Ak bubeșçe, Babuçca, Babunç, Bebisce, Bobaçce, Boğaz çiçeği, Bubaçça, Bubeççe, Bubeșçe, Kelkız çiçeği, Tıbbi papatya, Beyaz papatya, Sarı papatya, Kuzugözü papatya ve Akbaș otu Mayıs papatyasına verilen mahalli isimler olduğu bildirilmiștir. Matricaria recutita (Syn: Matricaria chamomilla) bitkisinin yanında çeșitli Anthemis, Chrysanthemum ve Tripleurospermum türlerine de halk arasında "papatya" adı verildiği bildirilmiștir. Halk arasında Anthemis cretica, Pseudocotula wildemanniana, Chrysanthemum coronarium ve Tripleurospermum monticolum'a sadece "papatya" adı verilirken, Anthemis nobilis 'e "Alman papatyası", A. cotula'ya "patıska çiçeği”, $A$. austriaca 'ya "kelemli", "Akbabatça", "Koyungözü papatya" adları da verilmektedir (Gül, 1995).

Mayıs papatyası öncelikle șifa bulmak isteyen alıcıların tercih ettiği bir bitki olmasına rağmen, pazarda onun yerine çoğu zaman köpek papatyasının satımasından dolayı tedarikçiler, perakendeciler ve özellikle tüketicilerde bilinç ve kamuoyu olușturulması amacıyla bu çalıșma yapılmıștır.

\section{Materyal ve Yöntem}

Bu çalışma 6 ilde (Siirt, Batman, Mardin, Diyarbakır, Gaziantep ve Șanlıurfa) faaliyet gösteren merkezi konumda, aktarlar çarșısının bulunduğu illerde aktarlar çarșısında ve müșteri yoğunluğunun fazla olduğu aktarlar gayeli örnekleme (Çiçek ve Erkan, 1996) yöntemi uygulanarak seçilmiș ve toplam 60 ișyerinden örnekler alınmıștır. Temin edilen örneklerin teşhisi Siirt Üniversitesi Fen Edebiyat Fakültesi 
Biyoloji Bölümü laboratuvarlarında yapılmıştır. Örneklerin teșhisinde "Flora of Turkey and the East Aegean Islands" adlı eserin 5. cildi kullanılmıștır (Davis 1975). Teșhis sonucu örneklerin Anthemis altissima L. olduğu belirlenmiștir. 2012 yllında Güner ve ark. tarafından yazılan Türkiye Bitkileri Listesi (Damarlı Bitkiler) isimli eserde Anthemis altissima L., Cota altissima (L.) J. Gay'nın sinonimi olarak verilmiștir. Bu durumda incelenen örneklerin Cota altissima oldukları tespit edilmiștir.

\section{Bulgular ve Tartıșma}

Yapılan teșhis çalıșmasının sonucunda bölgede mayıs papatyası adı altında satışı yapılan örneklerin neredeyse tamamının (\% 95.7) aslında Cota altissima (L.) J. Gay olan ve Türkiye'de köpek papatyası olarak bilinen türe ait olduğu tespit edilmiştir. Köpek papatyası, Türkiye'de 9'u endemik olmak üzere 15 , dünyada 49 türü bulunan Cota J. Gay cinsine ait bir türdür. Cota cinsi morfolojik olarak Anthemis'e benzemektedir. Fakat Cota cinsi Anthemis cinsinden akenlerindeki farklılıklarından dolayı ayrım göstermektedir (Özbek ve ark.2018). Cota altissima (L.) J.Gay dik, yarı tüylü, tek yıllıktır. Gövde genellikle üstte dallanmıs halde ve 20-60 cm boyundadır. Yapraklar 3-7 cm, oval-dikdörtgen șeklinde 2-3-pinnatisekt parçalı Iobların ucu akuminate 3-6 x 0.5-0.75 mm'dir. Kapitulum radiate, Pedunkullar kalınlașmıș halde, involukrumlar 1-2 cm genișliğinde, diştaki fillariler yumurtamsı șeklinde ve uçları akut, içtekiler dikdörtgenimsi șeklinde ve uçları düzdür. Reseptakulum yarıküremsi; paleae oblong-spathulate șeklindedir. Ray çiçekleri yaklașık 20, genellikle verimlidir (Davis 1975). Yapılan birçok çalıșmada (Javidnia ve ark. 2004; Rezaee ve ark. 2011; Rustaiyan ve ark. 2011; Saroglou ve ark. 2006) Cota altissima bitkisinin çiçek ve yapraklarında uçucu yağ içeriklerine bakılmıștır. Etno-botanik çalıșmalarda, hazımsızlık, boğaz ağrısı ve yara iyileștirici, kalp toniği, adet ağrısı, sarılık, mide rahatsızlığı ve öksürük de kullanıldığı bildirilmiș; ancak literatürde bunları doğrulayan herhangi bir bilimsel çalıșmaya rastlanmamıștır (Altundag ve Ozturk 2011; Amir ve ark, 2018; Bulut ve ark, 2017; Dolatkhah ve ark.,2014; Mamedov, 1996; Nejad ve ark., 2018; Pieronia ve ark., 2004; Pieroni ve Quave 2005).

Köpekpapatyasıuçucuyağında(-)- $\alpha$-Pinene, 2,4(10) -Thujadiene, Benzaldehyde, 1-Octen3-ol, $\delta$-2-Carene, Yamogi alcohol, Octanal, p-Cymene, 1,8-Cineole, cis-Ocimene, cis-Linalool; $\alpha$-Campholene aldehyde, cisChrysanthenyl acetate, $\alpha$-Copaene, Decanoic acid, trans-Caryophyllene, $\alpha$-Humulene, trans- $\beta$-Farnesene, (-)-Caryophyllene oxide bulunduğu bildirilmiștir (Vasiliki ve ark., 2006). Mayıs papatyasında ise bulunan en önemli bileșenler Bisabolol oxide a, Chamazulene, beta-Farnesene, Bisabolol oxide b, alphaBisabolol, Bisabolone oxide'dir. Bunların yanında daha az miktarda da olsan 1,8-Cineole (eucalyptol), Gamma-terpinene, beta Ocimene,

Çizelge 1. Çalıșmada toplanan örneklerin türlere göre dağılımı ve oranları (\%)

Table 1. At the Study distribution and proportions of collected samples by species (\%)

\begin{tabular}{|c|c|c|c|c|c|c|}
\hline iller & $\begin{array}{c}\text { Numune } \\
\text { Alınan } \\
\text { İșletme } \\
\text { Sayısı }\end{array}$ & Tespit Edilen Tür & $\begin{array}{c}\text { Mayıs } \\
\text { Papatyası } \\
\text { Sayısı }\end{array}$ & $\begin{array}{c}\text { Köpek } \\
\text { Papatyası } \\
\text { Sayısı }\end{array}$ & $\begin{array}{c}\text { Mayıs } \\
\text { Papatyası } \\
\text { Oranı (\%) }\end{array}$ & $\begin{array}{c}\text { Köpek } \\
\text { Papatyası } \\
\text { Oranı (\%) }\end{array}$ \\
\hline Batman & 5 & Cota altissima & - & 5 & 0 & 100 \\
\hline Diyarbakır & 22 & Cota altissima & - & 22 & 0 & 100 \\
\hline Gaziantep & 10 & Cota altissima & - & 10 & 0 & 100 \\
\hline Mardin & 7 & Cota altissima & - & 7 & 0 & 100 \\
\hline Siirt & 4 & Cota altissima & - & 4 & 0 & 100 \\
\hline Șanlıurfa & 12 & $\begin{array}{l}\text { a) Cota altissima } \\
\text { b) Matricaria recutita }\end{array}$ & 3 & 9 & 25 & 75 \\
\hline Toplam & 60 & & 3 & 57 & 4.3 & 95.7 \\
\hline
\end{tabular}


Artemisia ketone, Diacetone alcohol (tyranton), Spathulenol de vardır (Arslan, 2012). Burada da görüldüğü gibi bu iki bitkinin uçucu yağ kompozisyonları da birbirinden oldukça farklıdır ve bundan köpek papatyasının mayıs papatyası yerine kullanımının doğru olmayacağı düșünülmektedir.

Çizelge 1 incelendiğinde Batman'dan 5, Diyarbakır'dan 22, Gaziantep'ten 10, Mardin'den 7, Șanlıurfa'dan 12 olmak üzere toplam 60 aktardan 60 örnek alındığı görülmektedir. Alınan örneklerden 57 tanesinin köpek papatyası, sadece 3 tanesinin mayıs papatyası olduğu tespit edilmiştir. Toplamda örneklerin \%95.7'sinin köpek papatyası, yalnızca \%4.3'ünün mayıs papatyası olması dikkat çekicidir.

Everest ve Öztürk, 2005, Gürdal ve Kültür, 2013, Toksoy ve ark., 2010, Uysal ve ark., 2010'a göre Asteraceae familyasının birçok cinsi, çiçekler benzer olduğu için tıbbi papatya (Matricaria chamomilla) olarak satımaktadır (Akbulut ve Özkan, 2016). Anthemis spp. ve ayn ailenin Krizantem koronaryumu, Helichrysum stoechas ve Bellis perennis gibi türler buna örnek olarak verilebilir. Ayrıca Türkiye'nin farklı yerlerinde de çalışmamızı destekleyecek şekilde Cota altissima'nın aktarlarda "papatya" olarak satılıı̆ı bildirilmiștir (Akbulut ve Özkan, 2016).

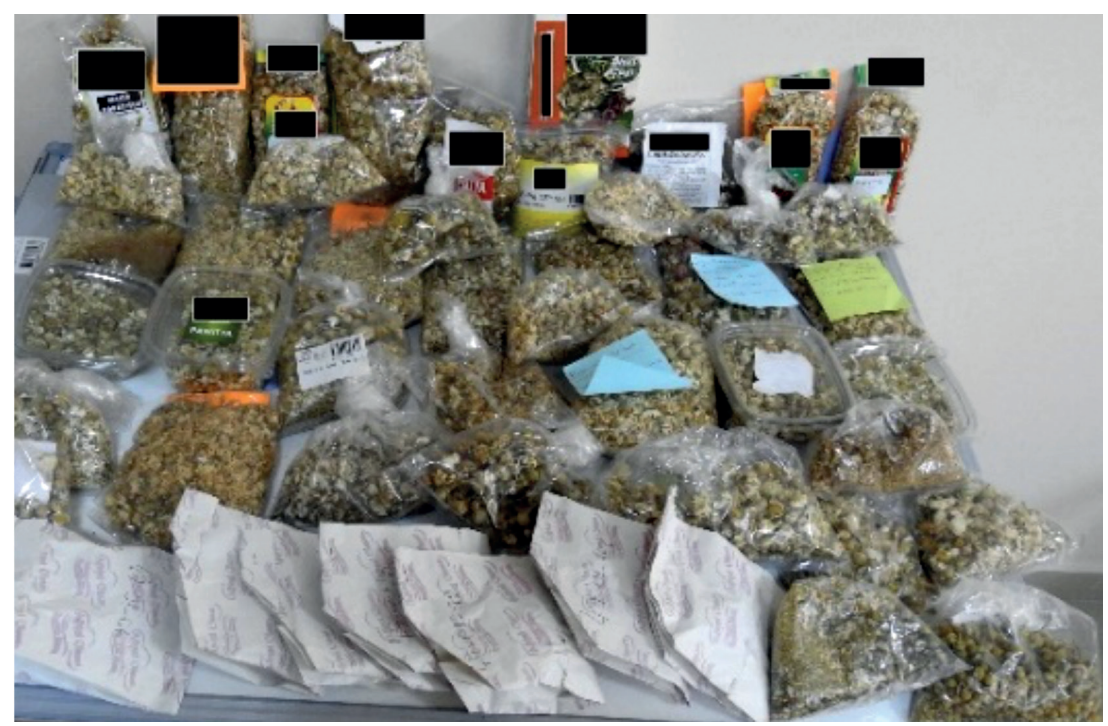

Șekil 1. Aktarlardan alınan örnekler

Figure 1. Samples from acthars

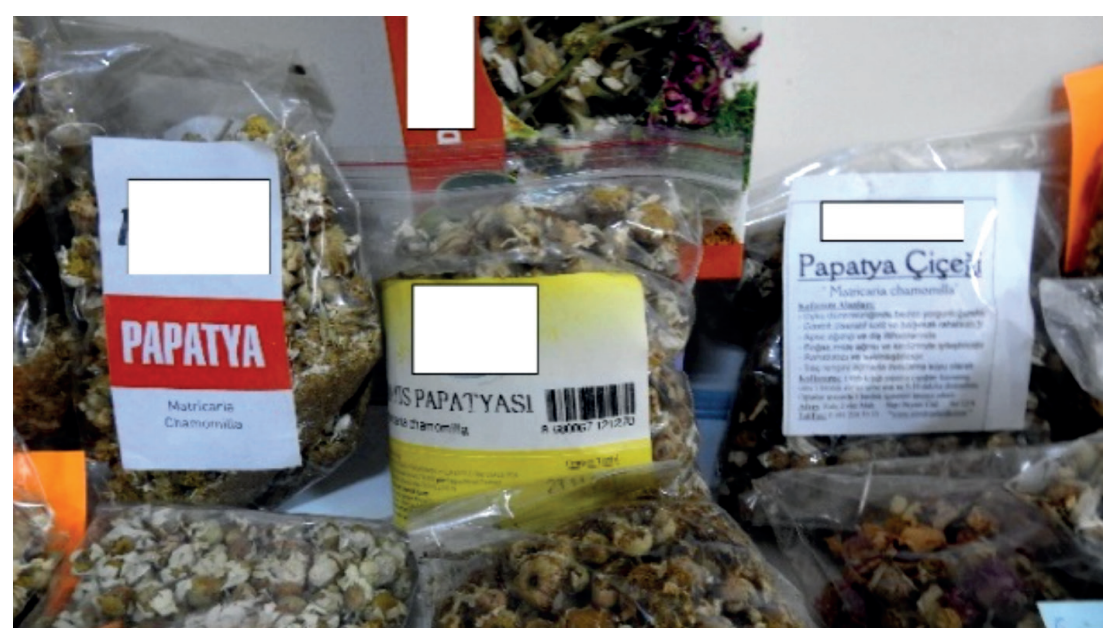

Șekil 2. Aktarlarda Mayıs papatyası olarak satılan köpek papatyaları

Figure 2. At Acthars; Dog daisies sold as May daisies 


\section{Sonuçlar}

Yapılan bu araștırma sonucunda aktarlarda mayıs papatyası yerine genellikle köpek papatyasının satıldığı tespit edilmiştir. Ayrıca tüketicilerin de bitkiyi tanımadıkları, bunun için de kendilerine verilen papatyanın mayıs papatyası olup olmadığını sorgulamadıkları tespit edilmiștir. Aynı zamanda aktarların büyük bir kısmının da mayıs papatyası diye sattıkları ürünün köpek papatyası olduğunu bilmedikleri gözlemlenmiștir (Şekil 2). Köpek papatyası (Cota altissima (L.) J Gay) türünün satılmasında, satılan türün ismine doğru olması ve tüketicinin aldığı ürünün gerçekte ne olduğunun, hangi durumlarda kullanılması gerektiğini bilmesi șartı ile aktarlarda satılmasında herhangi bir sakıncanın bulunması söz konusu değildir.

İnsan sağlığını ilgilendiren tıbbi ve aromatik bitkilerin pazarlanması mutlaka uzman kontrolörler tarafından düzenli bir şekilde denetlenmelidir. Çünkü bu çalıșmada tespit edildiği gibi çoğu zaman aktarlarda tıbbi ve aromatik bitkiler doğru isimleri ile satımamaktadır. Hatta bazen ismine doğru ürünü talep eden tüketicilerin zaman zaman tepki ile karșılaştığı da çalıșma sırasında tespit edilmiștir. Aynı zamanda toplanan örneklerin bilimsel bir çalıșmada kullanılacağını hisseden/ anlayan satıcıların satıștan vazgeçtikleri, fevri davrandıkları görülmüștür. Bu ve benzeri olumsuzlukların yașanmaması için tıbbi ve aromatik bitkiler sektöründeki en önemli paydașlardan olan aktarların tıbbi ve aromatik bitkiler konusunda ilgili bakanlık tarafından verilen eğitimler neticesinde alacakları sertifikaya sahip olmaları veya ilgili lisans-önlisans programlarından mezun olmaları zorunlu hale getirilmelidir. Ayrıca ilgili bakanlık uzmanları tarafindan periyodik olarak yapılması gereken denetimler neticesinde hem iyi niyetle de olsa satıcının hata yapması engellenecek hem de tüketicinin şifa bulmak amacıyla satın aldığı tıbbi ve aromatik bitkilerin yanlıs kullanımından kaynaklanacak olası sağlık problemlerinden korunması sağlanmıș olacaktır.

\section{Teșekkür}

$\mathrm{Bu}$ çalıșmada materyal olarak kullanılan papatyaların tür teșhisini yapan Dr. Öğr.Üyesi Mehmet FiDAN'a teșekkür ederim.

\section{Kaynaklar}

Abak, F., Akan, H., 2014. The flora of Asteraceae family in Șanlıurfa/Turkey Biological Diversity and Conservation 7/1 68-78

Akbulut, S., Özkan, Z.C., 2016. Herbalist-Customer Profile in Medicinal and Aromatic Herbs Trade: A Case Study of Kahramanmaraș, Kastamonu Üniversitsi, Orman Fakültesi Dergisi, , 16 (1): 246-252

Altundag, E., Ozturk, M., 2011. Ethnomedicinal studies on the plant resources of east Anatolia,Turkey Procedia Social and Behavioral Sciences 19, 756-777

Amir, S., Nejad, M., Bahmani, M., Shah, N.A., Sayed, A., Kopaei, M.R., 2018. Beliefs of herbal therapies of the community of The Ilam City of Ilam Province, Iran. Journal of Pharmacy \& Pharmacognosy Research, 6 (4): 299-317.

Arslan, D., 2012. Yalova Ekolojik Koșullarında Mayıs Papatyası (Matricaria recutita L.) Çeșitlerinde Farklı Ekim Zamanları ve Ekim Mesafelerinin Verim ve kalite özelliklerine etkisi. Ege Üniversitesi Fen Bilimleri Enstitüsü (Doktora Tezi) İzmir.

Arslan, N., Gürbüz, B., Gümüșçü, A., 2015. Açıklamalı tıbbi ve aromatik bitkiler rehberi. Ankara Üniversitesi Ziraat Fakültesi Ders Kitabı: 572, Yayın No:1620, Ankara.

Baghalian, K., Haghiry, A., Naghavi, M.R., Mohammadi, A., 2008. Effect of saline Irrigation water on agronomical and phytochemical characters of chamomile (Matricaria recutita L.). Scientia Horticulturae Volume 116 (4): 437-441.

Baydar, H., 2013. Tıbbi ve aromatik bitkiler bilimi ve teknolojisi (Genișletilmiș 4. Baskı). Süleyman Demirel Üniversitesi Ziraat Fakültesi Yayın No:51, Isparta.

Baytop, A., 1996. Farmasötik botanik ders kitabı. İstanbul Üniversitesi Eczacılık Fakültesi, Üniversite Yayın No:3637, Eczacılık Fakültesi Yayın No:58. İstanbul.

Baytop, T., 1999. Türkiye'de bitkiler ile tedavi (Ilaveli 2. Baskı). Nobel Tıp Kitap Evleri, İstanbul.

Bulut, G., Haznedaroğlu M.Z., Doğan, A., Koyu, H., Tuzlacı E., 2017 An ethnobotanical study of medicinal plants in Acipayam (DenizliTurkey) Journal of Herbal Medicine Volume 10, December, Pages 64-81

Bulut, G., Haznedaroğlu, M.Z., Doğan, A., Koyu, H,, Tuzlacı. E., 2017. An ethnobotanical study of medicinal plants in Acıpayam (Denizli-Turkey). Journal of Herbal Medicine, Volume 10:64-81.

Ceylan, A., 1996. Tıbbi bitkiler II (Uçucu Yağ Bitkileri). Ege Üniversitesi Ziraat Fakültesi Yayını No:481, izmir

Çiçek, A., Erkan, O., 1996. Tarım ekonomisinde araştırma ve örnekleme yöntemleri. GOÜ Ziraat Fakültesi Yayınları No:12, Ders Notları Serisi No:6, Tokat.

Davis, P.H., 1975. Flora of Turkey and The East Aegean Islands. Edinburgh University Press, Vol. 5, Edinburgh, UK. 
Dolatkhah, M., Dolatkhahi, A., Nejad, J.B., 2014. Ethnobotanical study of medicinal plants used in Arjan -Parishan protected area in Fars Province of Iran. Avicenna Journal of Phytomedicine, 4 (6): 402-412

Dolomiti Lucane, inland southern Italy, Journal of Ethnopharmacology, 95, 373-384

Gül, G., 1995. Matricaria chamomilla L. var. recutita Grierson üzerinde farmakognozik araștırmalar. Gazi Üniversitesi Sağlık Bilimleri Enstitüsü Farmakognozi Anabilim Dalı Yüksek Lisans Tezi, Ankara.

Güner, A., Aslan, S., Ekim, T., Vural, M., Babaç, M.T., 2012. Türkiye bitkileri listesi (damarlı bitkiler)1. Cilt. Flora Araștırmaları Derneği ve Nezahat Gökyiğit Botanik Bahçesi Yayını, İstanbul.

Hergenç, G., 2015. En son bilimsel veriler ıșığında beslenme, sağlık ve hastalıkta bitkiler (1.Baskı). Nobel Tıp Kitapevleri, İstanbul.

İşman, Ö.G., 2009. Matricaria recutita (Alman papatyası). Fitomed: Bilimsel Fitoterapi Dergisi, 2(10): 43-46.

Javidnia, K., Miri, R., Kamalinejad, M., Sarkarzadeh, H., Jamalian, A., 2004. Chemical composition of the essential oils of Anthemis altissima L. Grown in Iran. Flavour and Fragrance Journal 19: 213216.

Mamedov, N.A., 1996. Medicinal plants of compositae family in Karabakh folk medicine. International Symposium on Medicinal and Aromatic Plants, Amherst, Ma, August 27-30, 1995426 pp. 79-82.

Nejad, A.S.M., Bahmani, M., Shah N.A., Shah, S.A., Rafieian-Kopaei M., 2018. Beliefs of herbal therapies of the community of the llam city of Ilam province, Iran [Creencias de las terapias herbales de la comunidad de la ciudad de Ilam de la provincia de Ilam, Irán] Journal of Pharmacy \& Pharmacognosy Research, 6 (4), 299-317,

Özbek, M.U., Özbek, F, Vural, M., 2018. Achene morphology of the Genus Cota J.Gay (Asteraceae) from Turkey and its taxonomic significance. Turkish Journal of Botany, Volume 42: 208-223.
Pieroni, A., Quave, C.L., 2005. Traditional pharmacopoeias and medicines among Albanians and Italians in southern Italy: A comparison, Journal of Ethnopharmacology 101, 258-270

Pieronia, A., Quavec, C.L., Santorod, R.F., 2004. Folk pharmaceutical knowledge in the territory of the

Pirzad, A., Alyari, H., Shakiba, M.R., Salmasi, S.Z., Mohammadi, A., 2006. Essential oil content and composition of german chamomile (Matricaria chamomilla L.) at different irrigation regimes. Journal of Agronomy Volume5 (3): 451-455.

Rafieiolhossaini, M., Sodaeizadeh, H., Adams, A., De Kimpe, N., Van Damme, P., 2010. Effects of planting date and seedling age on agromorphological characteristics, essential oil content and composition of german chamomile (Matricaria chamomilla L.) grown in Belgium. Industrial Crops and Products Volume 31(1): 145-152

Rezaee, M.B., Jaimand, K., Assarih, M.H., 2011. Chemical constituents of the leaf and flower oils from Anthemis altissima L. var. altissima from Iran. Journal of Essential Oil Research Volume18(2): 152-153.

Rustaiyan, A., Azar, P.A., Moradalizadeh, M., Masoudi, S., Ameri, N., 2011. Volatile constituents of three compositae herbs: Anthemis altissima L. var. Altissima, Conyza canadensis (L.) Cronq. and Grantina aucheri Boiss. growing wild in Iran. Journal of Essential Oil Research, 16(6): 579-581.

Salamon, I., 2004. The Slovak gene pool of german chamomile (Matricaria recutita L.) and comparison in its parameters. Horticultural Science, 31(2): 70-75.

Saroglou, V., Dorizas, N., Kypriotakis, Z., Skaltsa, H.D., 2006. Analysis of the essential oil composition of eight anthemis species from Greece. Journal of Chromatography A, 1104, 313-322.

Zeybek, U., Haksel, M., 2011. Türkiye'de ve Dünyada önemli tıbbi bitkiler ve kullanımları (2. Baskı) Argefar ve Helvazcızade Sağlık Yayınları-1 İzmir. 